\title{
Pengaruh Komunikasi Persuasif dalam Penyuluhan Produksi Pangan Industri Rumah Tangga terhadap Perubahan Sikap Para Usaha Kecil Menengah (UKM) di Kota Bogor
}

\author{
Maria Fitriah \\ Ike Atikah Ratnamulyani \\ Maria_fitriah@yahoo.co.id/maria.fitria@unida.ac.id \\ Fakultas Ilmu Sosial dan Ilmu Politik, Program Studi Ilmu Komunikasi, \\ Universitas Djuanda Gedung B Lantai 3, Jalan Tol Ciawi No.1 Bogor, No \\ Hp. 081399308312
}

\begin{abstract}
The purposes of this research: (1) to analyse persuasive communication Bogor City Health Office in counseling Household Food Production Industry, (2) to analyse change of attitude the Small and Medium Enterprises (UKM) Bogor City, (3) designing persuasive communication to change attitudes the Small and Medium Enterprises (UKM) Bogor City, (4) to analyse the effect of persuasive communication Bogor City Health Office to change attitudes the Small and Medium Enterprises (UKM) Bogor City. This research conducting in Bogor City Health Office area on May 2015. Population of its research is around the Small and Medium Enterprises (UKM) Bogor City community. Sample of research the pain according random sampling amount 30 respondens. Collecting data conducted by observation, questioner, interview, and documentation study. Data analyses by spearman correlation with SPSS program.

Based on research result, persuasive Communication in Extension Food Safety Household Industrial Production has good category, changes in the attitude of the domestic industry has a very good category, the influence of persuasive communication Bogor City Health Department to change the attitude of the Small and Medium Enterprises with a correlation value of 0.494 and interpretation of the correlation coefficient being, design of persuasive communication to change attitudes, namely the existence of elements that include credibility communicator, attractions, and power as well as the elements of a message that includes the concept and format of messages that cause a change in attitude.
\end{abstract}

keyword: persuasive communication, education, attitude change

I. Pendahuan

\subsection{Latar Belakang}

Menurut Schumpetet (1934), entrepreneur mempunyai andil besar dalam pembangunan ekonomi melalui penciptaan inovasi, lapangan kerja, dan kesejahteraan.

Pembangunan industri bukan hanya untuk membangun pabrik atau peningkatan kapasitas industri, tetapi juga meningkatkan pertumbuhan lapangan kerja, meningkatkan kemakmuran dan kesejahteraan rakyat serta menumbuhkan inisiatif masyarakat dalam pembangunan industri (Hubeis, 2007 dalam Rohayati, 2015).

Radjasa dalam Diah (2014) mengatakan, pemerintah berupaya meningkatkan jumlah wirausaha di Indonesia sebagai salah satu langkah percepatan pembangunan ekonomi dengan memberikan fasilitas pelatihan, pendampingan, dan kredit modal bersama dengan berbagai pemangku kepentingan.

Industri pangan sebagai produsen pangan merupakan faktor penentu tersedianya pangan yang 
aman, bermanfaat, dan bermutu. Industri pangan nasional, khususnya industri rumah tangga, harus mampu bersaing di pasar global. Pemerintah harus melindungi masyarakat dari pangan yang berbahaya bagi kesehatan dan pangan yang tidak sesuai dengan standar mutu dan keamanan (Sumber: Dinas Kesehatan Kota Bogor). Pemerintah berkewajiban meningkatkan daya saing produksi pangan industri rumah tangga melalui peningkatan kesadaran dan motivasi produsen tentang pentingnya pengolahan pangan yang higienis (Badan POM RI, 2012).

Dinas Kesehatan (Dinkes) Kota Bogor melalui bidang pengujian pengawasan pangan memberikan sertifikasi P-IRT bagi pelaku usaha dengan adanya arahan serta pemahaman tentang stadarisasi yang harus dilalui serta kebersihan sanitasi tempat pengolahan usaha yang dimiliki. Menurut Kepala Bidang Pengujian dan Pengawasan Pangan (Kabid P3) Dinas kesehatan Kota Bogor Nuraeda, pengusaha pelaku home industry (industri rumahan) maupun badan usaha mengajukan permohonan serta kelengkapan produk yang dimiliki sesuai dengan keputusan Kepala Badan POM nomor. HK 03.1.23.04.12.22.05 untuk pengujian standar mutu produk olahan pangan, baik dari segi heginitas, campuran bahan tambahan pangan yang di perbolehkan maupun standar kemasan yang dimiliki. Survey lapangan ke tempat usaha juga dilakukan untuk mendapatkan sertifikasi P-IRT (Sumburi\&Ibrahim, 2014). Menurut Tuharea dkk (2009), penyuluhan merupakan salah satu pendidikan nonformal yang umumnya dilakukan.

Dinas Kesehatan melakukan penyuluhan dalam penyampaian informasi melalui Sertifikasi Produksi Pangan Industri Rumah Tangga (SPPIRT) dengan menggunakan komunikasi persuasif. Sesuai pernyataan Febriana (2014), usaha mengubah perilaku individu atau masyarakat luas dalam penyuluhan sosial dilakukan dengan pola-pola komunikasi persuasif yang sifatnya mempengaruhi. Menurut Anderson (1972), komunikasi persuasif didefinisikan sebagai perilaku komunikasi yang mempunyai tujuan mengubah keyakinan, sikap atau perilaku individu atau kelompok lain melalui transmisi beberapa pesan.

\subsection{Rumusan Masalah}

Berdasarkan latar belakang di atas, maka rumusan masalah dalam penelitian ini sebagai berikut:

1. Bagaimana komunikasi persuasif Dinas Kesehatan Kota Bogor dalam penyuluhan Produksi Pangan Industri Rumah Tangga?

2. Bagaimana perubahan sikap para Usaha Kecil Menengah (UKM) kota Bogor?

3. Bagaimana mendesain komunikasi persuasif terhadap perubahan sikap para Usaha Kecil Menengah (UKM) kota Bogor?

4. Bagaimana pengaruh komunikasi persuasif Dinas Kesehatan Kota Bogor terhadap perubahan sikap para Usaha Kecil Menengah (UKM)? 


\subsection{Tujuan Penelitian}

Berdasarkan rumusan masalah di atas, penelitian ini bertujuan untuk:

1. Menganalisis komunikasi persuasif Dinas Kesehatan Kota Bogor dalam penyuluhan Produksi Pangan Industri Rumah Tangga.

1 Menganalisis perubahan sikap para Usaha Kecil Menengah (UKM) kota Bogor.

2 Mendesain komunikasi persuasif terhadap perubahan sikap para Usaha Kecil Menengah (UKM) kota Bogor.

3 Menganalisis pengaruh komunikasi persuasif Dinas Kesehatan Kota Bogor terhadap perubahan sikap para Usaha Kecil Menengah (UKM).

\subsection{Kegunaan Penelitian}

\subsubsection{Kegunaan Teoritis}

Kegunaan teoritisnya yaitu Penelitian ini dapat menambah pengetahuan tentang komunikasi persuasif dalam perubahan sikap

\subsubsection{Kegunaan Praktis}

Dinas Kesehatan dapat menggunakan komunikasi persuasif yang baik dalam program penyuluhan tentang informasi produksi pangan sehingga dapat merubah sikap wirausaha.

\section{Kerangka Pemikiran}

$\mathrm{X}_{1}$. Komunikator dalam Komunikasi Persuasif

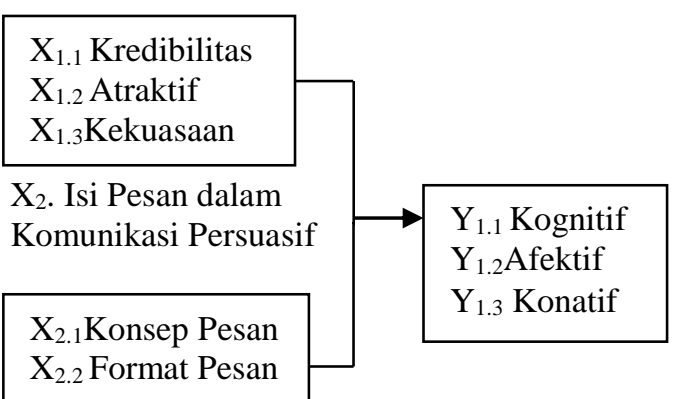

Gambar 2. Pengaruh Komunikasi Persuasif terhadap Perubahan Sikap Para UKM di Kota Bogor

Ha: Adanya pengaruh komunikasi persuasif terhadap perubahan sikap Para UKM di Kota Bogor

Ho: Tidak adanya pengaruh komunikasi persuasif terhadap

Perubahan sikap para UKM di Kota Bogor

\section{BAHAN DAN METODE}

Penelitian ini menggunakan deskriptif kuantitatif. Lokasi penelitian dilakukan di Dinas Kesehatan Kota Bogor pada bulan Mei tahun 2015. Populasi penelitian sebanyak 52 orang. Sesuai dengan pernyataan Roscoe dalam Sugiyono (2007), penelitian korelasional jumlah sampel minimal untuk memperoleh hasil yang baik adalah 30 responden. Maka penelitian ini diperoleh sampel sebanyak 30 responden.

Teknik pengumpulan data yang digunakan meliputi angket, observasi, wawancara, dan tinjauan pustaka. Analisis data pada penelitian ini menggunakan rumus rank spearman. Data dalam penelitian ini dianalisis dengan menggunakan beberapa prosedur statistik. Untuk mengetahui 
kriteria penafsiran dihitung dengan menggunakan sistem skoring, dalam penelitian ini skala pengukurannya menggunakan rumus Bakrie Siregar (1981) weight mean score (WMS) yaitu dengan dilakukan pembobotan nilai untuk setiap jawaban, dengan interval 1-5, sehingga data dari pengisian kuesioner disajikan dalam bentuk distribusi frekuensi dan tabulasi silang serta data yang diperoleh berskala interval dan ordinal.

(Tabel 1)
Data interval yang diperoleh antar kriteria, diperoleh dari rumus :

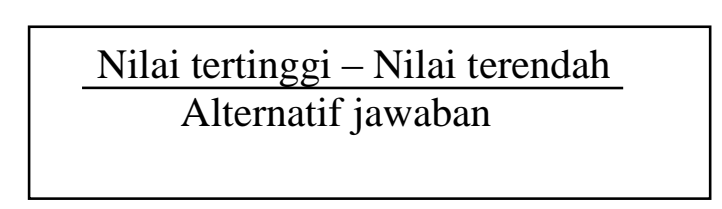

Berdasarkan rumus di atas, maka interval antar kriterianya: $5-1=\underline{0,8}$

\section{Tabel 1. Tanggapan Responden tentang Komunikasi Persuasif dalam Penyuluhan Keamanan}

\begin{tabular}{lll}
\hline Dimensi & Angka Penafsiran & Kriteria Penafsiran \\
\hline Komunikator & 3,85 & Baik \\
Isi Pesan & 4,31 & Sangat baik \\
Total & 4,08 & Baik \\
\hline
\end{tabular}

\section{Komunikasi Persuasif dalam Penyuluhan Keamanan Pangan Produksi Industri Rumah Tangga}

$\begin{array}{lll}\text { Mayoritas } & \text { responden } & \text { angka penafsiran 4,53. Menurut } \\ \text { menyatakan komunikasi persuasif } & \text { Thompson dalam (Rakhmat, 1992), isi } \\ \text { dinilai baik dengan angka penafsiran } & \text { pesan untuk komunikasi persuasif } \\ \text { 4,08. Ini dilihat isi pesan yang } & \text { harus menarik perhatian dan } \\ \text { disampaikan penyuluh sangat baik } & \text { menyentuh atau menggerakkan. } \\ \text { dengan angka penafsiran 4,31. Isi } & \begin{array}{l}\text { Sesuai dengan pernyataan } \\ \text { pesan adalah materi atau bahan yang }\end{array} \text { Learson (Syam\&Sugiana, 2007), } \\ \text { dipilih oleh komunikator untuk } & \text { menyatakan bahwa beberapa bentuk } \\ \text { menyatakan maksudnya } & \text { organisasi pesan di antaranya format } \\ \text { (Syam\&Sugiana, 2007). Dapat dilihat, } & \text { kronologis, format spasial, format } \\ \text { tanggapan yang sangat baik terhadap } & \text { topikal, format kausal, format } \\ \text { isi pesan dalam memberikan motivasi } & \text { pemecahan masalah, format berpikir } \\ \text { penggunaan label dan iklan pangan } & \text { kreatif, dan format pengembangan } \\ \text { sesuai persyaratan berlaku dengan } & \text { motivasional. (Tabel 1) }\end{array}$


Tabel 2. Rekapitulasi Variabel Perubahan Sikap

\begin{tabular}{|c|c|c|}
\hline Perubahan Sikap & Angka Penafsiran & Kriteria Penafsiran \\
\hline $\begin{array}{l}\text { Perubahan sikap terhadap pengetahuan tentang cara produksi pangan yang } \\
\text { baik }\end{array}$ & 4,4 & Sangat baik \\
\hline Perubahan sikap terhadap pengetahuan tentang sanitasi yang standar & 4,43 & Sangat baik \\
\hline $\begin{array}{l}\text { Perubahan sikap terhadap pengetahuan tentang bahan tambahan pangan } \\
\text { yang baik }\end{array}$ & 4,4 & Sangat baik \\
\hline $\begin{array}{l}\text { Perubahan sikap terhadap pengetahuan tentang keamanan dan mutu } \\
\text { pangan yang baik }\end{array}$ & 4,4 & Sangat baik \\
\hline $\begin{array}{l}\text { Perubahan sikap terhadap pengetahuan tentang label dan iklan pangan } \\
\text { sesuai persyaratan yang berlaku }\end{array}$ & 4,4 & Sangat baik \\
\hline Perubahan sikap terhadap pengetahuan tentang etika dan jejaring bisnis & 4 & Baik \\
\hline $\begin{array}{l}\text { Perubahan sikap terhadap pemahaman tentang cara produksi pangan yang } \\
\text { baik }\end{array}$ & 4,4 & Sangat baik \\
\hline Perubahan sikap terhadap pemahaman tentang sanitasi yang standar & 4,33 & Sangat baik \\
\hline $\begin{array}{l}\text { Perubahan sikap terhadap pemahaman tentang bahan tambahan pangan } \\
\text { yang baik }\end{array}$ & 4,23 & Baik \\
\hline $\begin{array}{l}\text { Perubahan sikap terhadap pemahaman tentang keamanan dan mutu } \\
\text { pangan yang baik }\end{array}$ & 4,26 & Bik \\
\hline $\begin{array}{l}\text { Perubahan sikap terhadap pemahaman tentang label dan iklan pangan } \\
\text { sesuai persyaratan yang berlaku }\end{array}$ & 4,3 & Sangat baik \\
\hline Perubahan sikap terhadap pemahaman tentang etika dan jejaring bisnis & 4 & Baik \\
\hline $\begin{array}{l}\text { Perubahan sikap terhadap kepuasan tentang cara produksi pangan yang } \\
\text { baik }\end{array}$ & 4,23 & Baik \\
\hline Perubahan sikap terhadap kepuasan tentang sanitasi yang standar & 4,26 & Baik \\
\hline $\begin{array}{l}\text { Perubahan sikap terhadap kepuasan tentang bahan tambahan pangan yang } \\
\text { baik }\end{array}$ & 4,13 & Baik \\
\hline $\begin{array}{l}\text { Perubahan sikap terhadap kepuasan tentang keamanan dan mutu pangan } \\
\text { yang baik }\end{array}$ & 4,13 & Baik \\
\hline $\begin{array}{l}\text { Perubahan sikap terhadap kepuasan tentang label dan iklan pangan sesuai } \\
\text { persyaratan yang berlaku }\end{array}$ & 4,23 & Baik \\
\hline Perubahan sikap terhadap kepuasan tentang etika dan jejaring bisnis & 4 & Baik \\
\hline $\begin{array}{l}\text { Perubahan sikap terhadap tindakan tentang cara produksi pangan yang } \\
\text { baik }\end{array}$ & 4,53 & Sangat baik \\
\hline Perubahan sikap terhadap tindakan tentang sanitasi yang standar & 4,56 & Sangat baik \\
\hline $\begin{array}{l}\text { Perubahan sikap terhadap tindakan tentang bahan tambahan pangan yang } \\
\text { baik }\end{array}$ & 4,56 & Sangat baik \\
\hline $\begin{array}{l}\text { Perubahan sikap terhadap tindakan tentang keamanan dan mutu pangan } \\
\text { yang baik }\end{array}$ & 4,56 & Sangat baik \\
\hline $\begin{array}{l}\text { Perubahan sikap terhadap tindakan tentang label dan iklan pangan sesuai } \\
\text { persyaratan yang berlaku }\end{array}$ & 4,73 & Sangat baik \\
\hline Perubahan sikap terhadap tindakan tentang etika dan jejaring bisnis & 4,46 & Sangat baik \\
\hline Total & $103,93 / 24=4,33$ & Sangat baik \\
\hline
\end{tabular}




\section{Perubahan Sikap Para Usaha Kecil Menengah (UKM) di Kota Bogor}

$$
\text { Umumnya respoden telah }
$$
melakukan perubahan sikap setelah mendapatkan informasi dari penyuluhan. Ini dibuktikan dengan angka penafsiran 4,33 pada kategori sangat baik. Sikap responden berubah sangat baik terhadap pengetahuan tentang cara produksi pangan yang baik, sanitasi yang standar, bahan tambahan pangan yang baik, keamanan dan mutu pangan yang baik, label dan iklan pangan sesuai persyaratan yang berlaku. Responden juga berubah sikapnya sangat baik terhadap pemahaman tentang cara produksi pangan yang baik, sanitasi yang standar, serta label dan iklan pangan sesuai persyaratan yang berlaku. Tindakan responden pun berubah sikapnya sangat baik terhadap cara produksi pangan yang baik, sanitasi yang standar, bahan tambahan pangan yang baik, keamanan dan mutu pangan yang baik, label dan iklan pangan sesuai persyaratan yang berlaku, serta etika dan jejaring bisnis. (Tabel 2)

Tabel 3. Pengaruh Komunikasi Persuasif terhadap Perubahan Sikap Para Usaha Kecil Menengah (UKM) Kota Bogor

\section{Nonparametric Correlations}

\begin{tabular}{|c|c|c|c|c|}
\hline \multicolumn{5}{|c|}{ Correlations } \\
\hline & & & $\begin{array}{c}\text { Komunikasi } \\
\text { Persuasif }\end{array}$ & $\begin{array}{l}\text { Perubahan } \\
\text { Sikap UKM }\end{array}$ \\
\hline \multirow[t]{8}{*}{ Spearman's rho } & Komunikasi Persuasif & Correlation & 1.000 & $.494^{* *}$ \\
\hline & & Coefficient & & \\
\hline & & Sig. (2-tailed) & & .006 \\
\hline & & $\mathrm{N}$ & 30 & 30 \\
\hline & Perubahan Sikap UKM & Correlation & $.494^{* \star}$ & 1.000 \\
\hline & & Coefficient & & \\
\hline & & Sig. (2-tailed) & .006 & \\
\hline & & $\mathrm{N}$ & 30 & 30 \\
\hline
\end{tabular}

**. Correlation is significant at the 0.01 level (2-tailed). 


\section{Pengaruh Komunikasi Persuasif terhadap Perubahan Sikap Para Usaha Kecil Menengah (UKM) Kota Bogor}

Berdasarkan hasil olah data SPSS diperoleh nilai korelasi sebesar 0,494 . Ini dikatakan terdapat pengaruh antara komunikasi persuasif Dinas Kesehatan Kota Bogor terhadap perubahan sikap para Usaha Kecil Menengah (UKM) dengan interpretasi koefisien korelasi sedang. Koefisien korelasi bertanda positif yang menggambarkan arah hubungan positif atau searah artinya semakin tinggi atau semakin baik komunikasi persuasif Dinas Kesehatan Kota Bogor maka semakin tinggi pula perubahan sikap para Usaha Kecil Menengah (UKM). Taraf signifikansi dengan tanda bintang dua artinya bahwa pengaruh komunikasi persuasif terhadap perubahan sikap para Usaha Kecil Menengah (UKM) adalah signifikan. Dapat dilihat dari nilai signifikansi sebesar 0,006 (kurang dari 0,05). (Tabel 3)

\section{Desain Komunikasi Persuasif terhadap Perubahan Sikap Para Usaha Kecil}

\section{Menengah (UKM) di Kota Bogor}

Desain Komunikasi Persuasif dapat digambarkan sebagai berikut:

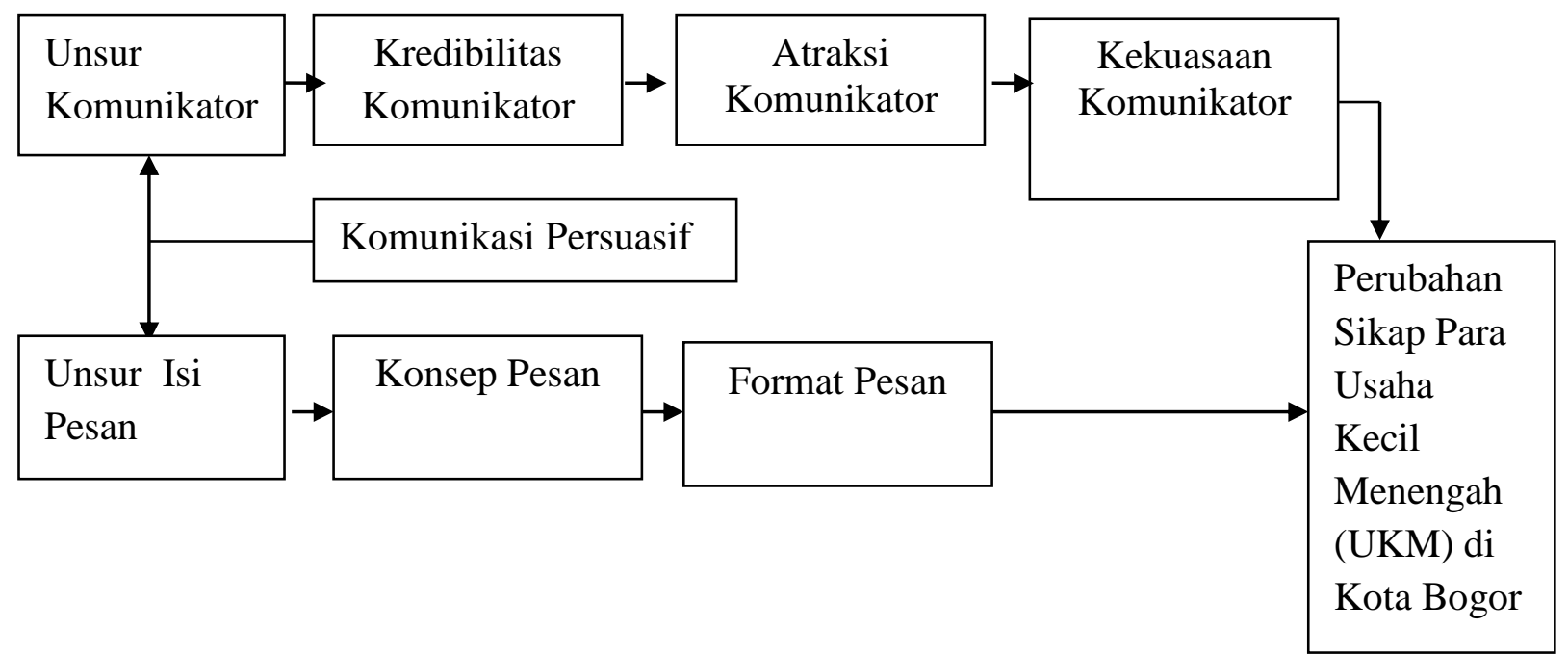

Gambar 2. Desain Komunikasi Persuasif terhadap Perubahan Sikap Para Usaha Kecil Menengah

A. Kredibilitas Komunikator dalam Komunikasi Persuasif
Kredibilitas komunikator dapat dilihat dalam kemampuan menjelaskan informasi, kemampuan memecahkan masalah, dan kemampuan penggunaan 
bahasa. Berdasarkan hasil penelitian, penyuluh sebagai komunikator dalam penyuluhan Produksi Pangan Industri Rumah Tangga (PIRT) dinilai sangat baik terhadap kemampuan menjelaskan informasi, informasi yang dipercaya, dan kemampuan memecahkan masalah.

Kredibilitas berkenaan dengan sifat-sifat komunikator yaitu keahlian dan kepercayaan. Keahlian adalah kesan yang dibentuk komunikan tentang kemampuan komunikator dalam hubungannya dengan topik yang dibicarakan. Komunikator yang dinilai tinggi dianggap sebagai cerdas, mampu, ahli dan berpengalaman (Aristoteles dalam Rakhmat, 2001).

\section{B. Atraksi Komunikator dalam Komunikasi Persuasif}

Umumnya responden menyatakan baik terhadap penilaian penyuluh sebagai komunikator dalam atraksi. Hal ini ditunjukkan dengan angka penafsiran 4,13 dengan kategori baik pada penampilan komunikator dan 4,23 dengan kategori baik pada keramahan komunikator.

\section{Kekuasaan Komunikator dalam Persuasif}

Hasil penelitian berdasarkan analisa menyatakan bahwa kekuasaan terhadap penyuluh yang memiliki jabatan saja melakukan komunikasi persuasif yang menarik dalam penyuluhan memiliki kategori sedang (kurang baik) dengan angka penafsiran 2,86 . Sedangkan responden mengikuti saran-saran penyuluh yang memiliki jabatan saja sebagai kekuasaan penyuluh dinilai dengan kategori buruk dengan angka penafsiran 22,23.

\section{Isi Pesan dalam Komunikasi}

Persuasif

Persuasi yang efektif adalah kemampuan untuk menyampaikan suatu pesan dengan cara membuat audiens (pembaca atau pendengar) merasa mempunyai pilihan dan membuat mereka setuju. Berdasarkan hasil penelitian, mayoritas responden menyatakan komunikasi persuasif dinilai baik dengan angka penafsiran 4,08. Hal ini dilihat isi pesan yang disampaikan penyuluh sangat baik yang ditunjukkan dengan angka penafsiran 4,31 .

Isi pesan adalah materi atau bahan yang dipilih oleh komunikator untuk menyatakan maksudnya (Syam\&Sugiana, 2007). Larson (1986) dalam Syam\&Sugiana (2007) menyatakan bahwa beberapa bentuk organisasi pesan di antaranya format kronologis, format spasial, format topikal, format kausal, format pemecahan masalah, format berpikir kreatif, dan format pengembangan motivasional.

Sunarjo (1997) menyimpulkan sikap dari beberapa ahli, sikap sebagai suatu predisposisi yang merupakan kesediaan untuk bertindak atau berperilaku dalam komponen kognitif, afektif, dan behavior (konatif) yang bersifat positif maupun negatif. 


\section{Perubahan Sikap Para Usaha Kecil Menengah di Kota Bogor Berdasarkan Aspek Kognitif, Afektif, dan Konatif}

Sunarjo (1997) menyimpulkan sikap dari beberapa ahli, sikap sebagai suatu predisposisi yang merupakan kesediaan untuk bertindak atau berperilaku dalam komponen kognitif, afektif, dan behavior (konatif) yang bersifat positif maupun negatif. Perubahan sikap para usaha kecil menengah melalui komunikasi persuasif dinilai dengan kategori sangat baik pada angka penafsiran 4,33 .

\section{KESIMPULAN DAN SARAN}

\section{Kesimpulan}

1. Komunikasi Persuasif dalam Penyuluhan Keamanan Pangan Produksi Industri Rumah Tangga memiliki kategori baik dengan angka penafsiran 4,08

2. Perubahan sikap para industri rumah tangga memiliki kategori sangat baik dengan angka penafsiran 4,33

3. Adanya pengaruh antara komunikasi persuasif Dinas Kesehatan Kota Bogor terhadap perubahan sikap para Usaha Kecil Menengah (UKM) dengan nilai korelasi sebesar 0,494 dan interpretasi koefisien korelasi sedang.

4. Desain komunikasi persuasif terhadap perubahan sikap yaitu adanya unsur-unsur komunikator yang meliputi kredibilitas, atraksi, dan kekuasaan serta unsur-unsur pesan yang meliputi konsep dan format pesan yang menimbulkan perubahan sikap para UKM di kota Bogor. Kredibilitas komunikator sangat tinggi dalam kemampuan menjelaskan informasi, kemampuan memberikan informasi yang dipercaya, dan kemampuan memecahkan masalah. Selain itu, atraksi penyuluh sebagai komunikator dalam penampilan dan keramahan memiliki kategori baik. Kekuasaan penyuluh terhadap penyuluh yang memiliki jabatan saja yang informasinya menarik dengan kategori sedang dan penyuluh yang memiliki jabatan saja yang saran-sarannya diikuti dengan kategori buruk. Sementara itu, konsep isi pesan dalam kesesuaian informasi dengan kebutuhan memiliki kategori sangat baik, materi sesuai dengan topik memiliki kategori sangat baik, dan pemberian panduan atau handout materi memiliki kategori baik. Format isi pesan memiliki kategori sangat baik dalam motivasi untuk melakukan cara produksi pangan yang baik dan motivasi untuk melakukan sanitasi yang standar, motivasi untuk menggunakan bahan tambahan pangan yang baik, motivasi untuk melakukan keamanan dan mutu pangan yang baik, motivasi untuk menggunakan label dan iklan pangan sesuai persyaratan yang berlaku, serta motivasi untuk memiliki etika bisnis dan jejaring bisnis. 
ISSN 1693-3699 (Cetak)

ISSN 2442-4102

\section{Saran}

Penyuluh sebagai komunikator dalam melakukan komunikasi persuasif harus dapat lebih terampil dalam penggunaan bahasa, penampilan, dan keramahan.

\section{DAFTAR PUSTAKA}

Anderson, Kenneth.1972. Introduction to Communication Theory And Practice. Publisher. mings Pub. Co. Michigan: The University of Michigan

Diah. 2014. Pemerintah Berupaya Tingkatkan Jumlah Wirausaha Diunduh pada tanggal $12 \mathrm{Mei}$ 2014.

Febriana, Early. 2014. Komunikasi Persuasif dalam Penyuluhan Sosial

Diunduh pada tanggal 24 Maret 2014. (www.kemsos.go.id)

Rakhmat, Jalaluddin. 2001. Psikologi Komunikasi. Bandung: Remaja Rosdakarya.

Rohayati, dkk. 2015. Efektivitas Pembiayaan dan Strategi Pengembangan Usaha Paving Blok di PD Telaga Jaya Blok Tangerang. Vol 10, No 1. ISSN 2085-8418. Bogor: Jurnal Manajemen Pengembangan Industri Kecil Menengah . (http://journal.ipb.ac.id/index. php/jurnalmpi/). Diakses pada tanggal 17 Oktober 2015
Jurnal Komunikasi Pembangunan Juli 2015. Vol.13, No.2

Schumpeter, J.A. 1934. In Theory of Economic Development: an Inquiry into Profits, Capital, Credit, Interest, and The Business Cycle. Newyork: Oxford University Press (http://www.antarajabar.com)

Sugiyono. 2010. Metode Penelitian Administasi. Bandung : Alvabeta.

Sumburi\&Ibrahim. 2014. Standarisasi Pengajuan P-IRT Bagi Produk IKM Kota Bogor.

Diunduh16 Januari 2014. (Gesitnews.com)

Sunarjo, Djoenaesih. 1997. Opini publik. Yogyakarta : Liberty

Syam\&Sugiana. 2007. Perencanaan Pesan dan Media. Jakarta: Universitas Terbuka

Tuharea dkk. 2009. Komunikasi dalam Perspektif Penyuluhan.

Diakses pada tanggal 23 Januari 2009. (http://fauziahadriyani.blogspot .com) 